\title{
Strategic voting in German constituencies
}

\author{
Michael Herrmann*, Franz Urban Pappi \\ Mannheimer Zentrum für Europäische Sozialforschung (MZES) A5, 6, 68159 Mannheim, Germany
}

Received 1 February 2007; revised 14 September 2007; accepted 31 October 2007

\begin{abstract}
We investigate strategic voting at German Bundestag elections. The common intuition about strategic voting holds that supporters of small party candidates split their ticket and cast a constituency vote for the candidate of a viable large party. We show that there is more potential for strategic voting than previously admitted. Based on the multiparty calculus of voting framework, we formulate a decision-theoretic model that allows us to take the full range of situations into account, that voters may encounter in their local constituencies. Applying this model to survey data from the 1998 and 2002 federal elections, we find that voters make use of sophisticated balloting, given the chance to influence the outcome of the constituency election. While the focus of this paper is on Germany, the approach we take is applicable to single seat elections in other countries as well.
\end{abstract}

(c) 2007 Elsevier Ltd. All rights reserved.

Keywords: Strategic voting; Single member districts; German elections; Calculus of voting

\section{Introduction}

In every general election roughly half the members of the German parliament (Bundestag) are elected from local constituencies. In each constituency, a single seat is awarded to the candidate who wins a plurality of the vote. All other votes are discarded. Such "winner takes all" or "first past the post" (FPTP) election rules disfavor candidates with low electoral prospects and make any vote for such candidates essentially wasted. To avoid wasting their vote on hopeless candidates voters sometimes switch to less preferred but more promising candidates, usually one of the top two contenders. Such voting behavior is termed strategic

\footnotetext{
* Corresponding author. Tel.: +49 (0)621 181 2856; fax: +49 (0)621 1812845 .

E-mail address: michael.herrmann@mzes.uni-mannheim.de (M. Herrmann).
}

or tactical and it differs from naïve voting insofar as voters deliberately seek to influence the outcome of the election instead of merely revealing their preference for a certain candidate.

Strategic voting is interesting insofar as electoral outcomes are not pre-determined by voters' preferences, which are more or less stable over the course of an election, but also by short-term swings in support from weak to strong candidates. If voters are short-term responsive to the electoral situation, strong candidates, in a close race, will be able to attract votes from supporters of weaker candidates. The extent to which voters adjust their behavior to the electoral situation thus has important implications for party strategy. For example, in running constituency campaigns, parties of the leading candidates may draw off support from weaker candidates by portraying the situation as a neck-and-neck race. In this paper we will examine the responsiveness of German voters to electoral competition in single 
seat elections. We ask: Do German voters cast strategic candidate votes? An answer to this question might help evaluate the potential of parties to influence constituency outcomes and also contribute to our understanding of the boundaries of voter sophistication in German federal elections.

When designing the German electoral system after World War II, the idea of adopting a pure FPTP system had strong support among several members of the parliamentary council. Post-war military government and the Christian Democrats (with support from the German Party, DP) strongly favored FPTP over proportional representation (PR). However, opposition by Social Democrats and the Liberal Party eventually led to the adoption of a mixture of PR and single seat constituencies, which is hitherto employed in federal elections (Bawn, 1993). Despite their long-standing presence in German politics, constituency elections have not received much scholarly attention. ${ }^{1}$ Common wisdom among observers and scholars of German politics, as well as most German voters, suggests that the PR vote is more important than the constituency vote for determining parties' seat shares in parliament. Electoral law prescribes that constituency candidates merely fill seats allocated to their party according to proportional representation. Under normal circumstances, they do not add extra seats to their party. Consequently one might argue that voters should not care very much about who wins their constituency since it would not affect parties' seat shares in parliament. Notwithstanding such claims, we believe there are at least three reasons why the constituency ballot should be important to voters.

First, the importance of the PR over the candidate vote is to a large part an empirical phenomenon not an institutional fact. Electoral law guarantees successful constituency candidates a mandate even if their party's state-wide share of PR votes provided them with an insufficient number of parliamentary seats. Such excess seats (Überhangmandate) increase parties' seat shares beyond the level of regular PR allocation. While excess seats have long been considered unlikely and rare, their occurrence has markedly increased in the post reunification period. On average $3.5 \%$ of all constituency candidates since 1990 obtained excess seats. The most recent election of 2005 even witnessed an all time high of $5 \%$. Winning those additional seats may be decisive for forming governmental majorities. As it is somewhat hard to predict, though, which constituencies will be more likely to yield excess seats, any

\footnotetext{
${ }^{1}$ See Wüst et al. (2006) for a recent counter-example.
}

constituency outcome bears some importance and thus voters should care about it.

Second, even if most seats are allocated according to $\mathrm{PR}$, it may still play a role for the individual voter, whether those seats are filled with rank-and-file party delegates or representatives from their local environment. Nomination of constituency candidates is normally carried out by small boards of local party delegates (Kreisdelegiertenversammlungen), with little outside influence by higher party executives. Party list members, by contrast, are elected on state-wide party conventions (Landesparteitage). Thus, while list members are likely to be selected on the basis of partisan assets (such as loyalty, ideology or technocratic skill), nomination of constituency candidates should be rather guided by their overall attractiveness to local constituents, not only to partisans but voters in general. The greater detachedness of constituency candidates from their party grassroots creates a subtle incentive for supporters of hopeless candidates to cast an alternative vote: As a typical example, consider a supporter of the FDP in a constituency where the margin of victory between CDU and SPD candidates is small. Assuming her second preference is CDU, she might ask herself: 'Given that my vote will be decisive, does it make a difference if I switched to the candidate of CDU?' The answer is yes, because if the CDU candidate gets elected he will fill a seat that would otherwise fall to a "faceless" party list member who does not hold any interest whatsoever in her constituency. By giving her vote to the CDU candidate the voter may effectively increase the similarity between CDU and herself as a constituent. Thus even if the constituency outcome would not alter parties' seat shares in parliament, influencing the composition of parliamentary fractions still serves as a motive for sophisticated balloting.

A third argument for the importance of constituency elections is also tied to candidates' party affiliation. Given that a voter evaluates candidates mainly on the basis of their party affiliation, it should not be irrelevant to her, whether she is being represented by a candidate from one or another party. Hence if the candidate from her preferred party is out of the race, she should be likely to switch to the candidate of a less preferred party in order to avoid the victory of a candidate from a party she does not like at all.

Taken together, we believe that there are good reasons for voters to care about the outcome of constituency elections and to vote strategically. The extent to which German voters actually make use of strategic balloting is ultimately an empirical question and we address it accordingly. Our findings suggest that German 
voters, indeed, cast constituency votes in ways predicted by strategic voting theory.

\section{Strategic voting in German constituency elections}

In the context of the German mixed PR plurality system, the notion of strategic voting is usually tied to the constituency ballot. While there is some value in the claim that German voters also cast strategic PR votes (Gschwend, 2007), we shall use the term 'strategic voting' exclusively to designate voter behavior in singlemember plurality elections. Previous studies have addressed the question of strategic voting mainly through analyses of aggregate vote statistics. ${ }^{2}$ For example, Cox (1997) and Bawn (1999) examine gaps between candidate and party vote shares across constituencies and find that, in close constituency elections, those gaps increase in favor of major party candidates and to the detriment of minor party candidates. If one assumes that a party's true underlying level of support can be inferred from the number of list votes, the observed differences should be the result of split voting by small party supporters who cast their constituency vote for a viable major party candidate.

As pointed out in the literature, though, there may be other reasons for splitting one's ticket between a large and a small party, such as protest voting by large party supporters (i.e. when they perceive the constituency race as a foregone conclusion) (Cox, 1997), expressing one's preference for a particular coalition (Roberts, 1988; Schoen, 1999; Pappi and Thurner, 2002), or strategic balloting in reverse order, i.e. a sincere constituency vote but a strategic party list vote (Gschwend, 2007). The latter type of strategic voting follows from preelectoral coalition announcements by German parties combined with the threat confronting small parties via the 5\% threshold of representation. Together these two features may cause some voters, who would rather support a major party, to give their PR vote to its junior coalition partner, in order to avoid the victory of the opposing coalition (threshold insurance: Cox, 1997, 197).

Given these alternative explanations, the validity of aggregate analyses in confirming strategic voting appears somewhat limited. More insight could be gained from additional analyses on the individual level, controlling for the different motivations voters may hold. Along these lines Pappi and Thurner (2002) find evidence for

\footnotetext{
${ }^{2}$ See Fisher (1973), Jesse (1988), Cox (1997), Bawn (1999), Schoen (1999), Gschwend et al. (2003).
}

the coalition preference hypothesis, and Gschwend (2007) successfully shows that the most frequently observed patterns of ticket splitting can be explained either by a 'wasted vote' or a 'coalition insurance' strategy.

Departing from these studies, we will focus exclusively on the constituency ballot. This enables a more direct test for strategic voting and also provides us with predictive estimates of the extent to which voters engage in this kind of behavior. It also allows for a much more detailed examination of voter responsiveness to electoral incentives. In fact, a major drawback of all previous attempts lies in the classification of viable and non-viable candidates. Previous studies have only regarded major party candidates (i.e. CDU and SPD) as viable and thus identified likely strategic voters solely among small party supporters, i.e. FDP, Greens, or PDS. Convenient as such a distinction may be for addressing electoral competition in West Germany, it misses out some of the most important aspects of electoral competition in East German constituencies. East German voters are faced with an essentially more diverse and complex electoral environment, which in turn provides them with more options for strategic voting than previously admitted.

To see how the electoral situation differs between East and West German constituencies, consider the diagrams in Figs. 1-3. Each figure displays the distribution of constituency results for one of the three most recent Bundestag elections in simplex form. ${ }^{3}$ On the left-hand side of each figure the vote shares of SPD and CDU candidates (i.e. CSU candidates for Bavarian constituencies) are plotted against the total share of all other candidates. The three right-hand side diagrams of each figure display the vote shares of FDP, Greens and PDS candidates against the shares of SPD and CDU candidates. The top right-hand side diagram, for instance, plots the vote shares of CDU, SPD and PDS candidates relative to each other, excluding other candidates' vote shares. Hence one can interpret the right-hand side diagrams as indicating the relative strengths of the respective candidates in every constituency. ${ }^{4}$

\footnotetext{
${ }^{3}$ Simplex representation exploits the fact that election results are bounded by the constraint that vote shares must add to one. An otherwise three-dimensional plot of party A's vote share against party B's and C's vote shares can thus be reduced to a two-dimensional equilateral triangle, since all election outcomes lie on a triangular plane, defined by the points $(1,0,0)$ to $(0,1,0)$ to $(0,0,1)$. Data on election results can be obtained from the bureau of the federal elections officer (Bundeswahlleiter) at http://www.bundeswahlleiter.de.

${ }^{4}$ Detailed explanations of these diagrams and their application with respect to multiparty competition can be found in Grofman et al. (2004), Gschwend and Leuffen (2005), Katz and King (1999), Miller (1977), and Upton (1994).
} 


\section{+ MODEL}
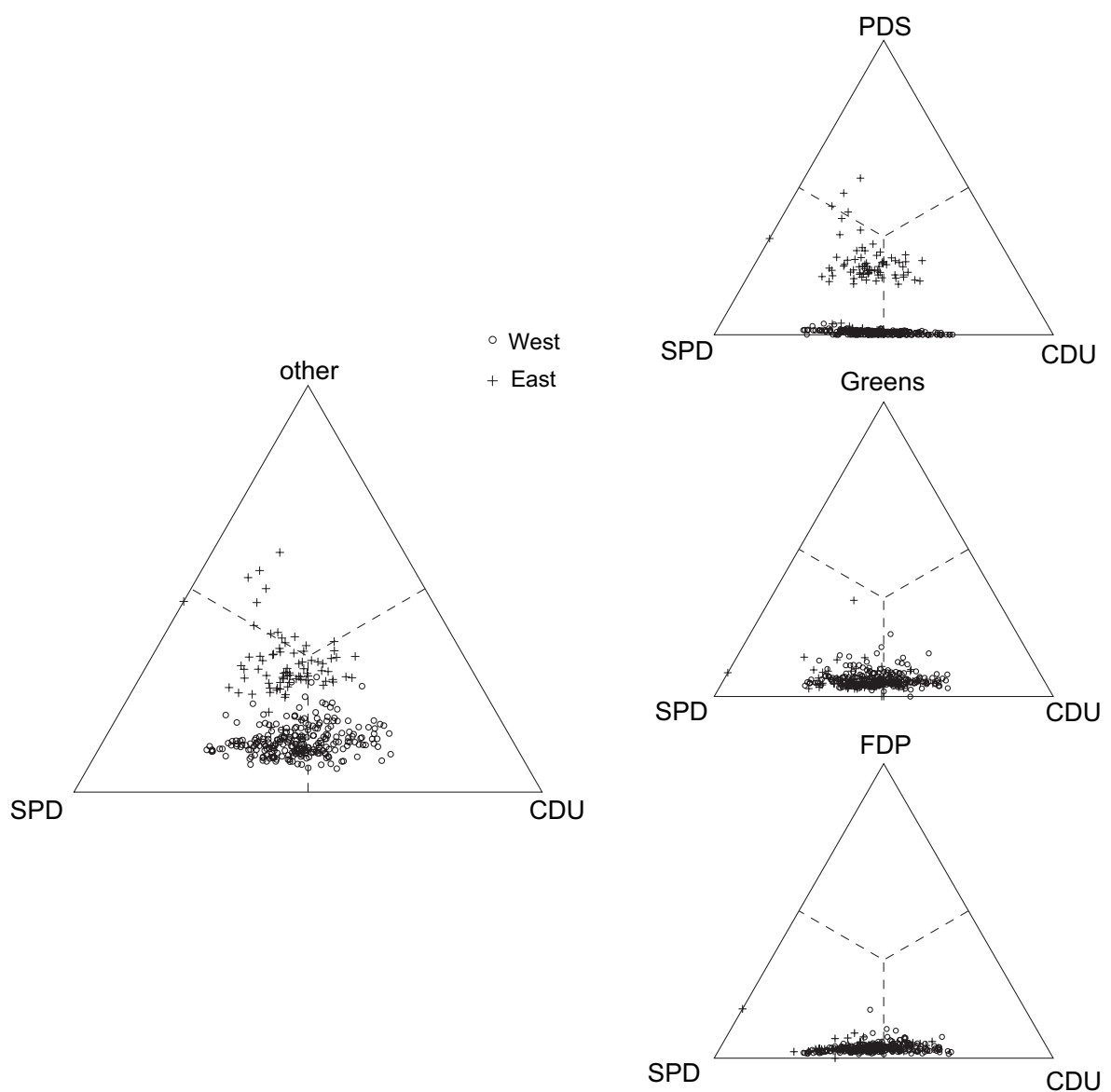

Fig. 1. Constituency results in $1998(N=328)$.

Interpretation of these diagrams is straightforward. The closer a district result is to one of the three vertices the larger the vote share of the respective party's candidate in that constituency. Consider, for instance, the left-hand side diagram in Fig. 1. The closer a result is to the CDU vertex, the larger the CDU candidate's vote share in that particular district. An outcome in which the CDU candidate wins the entire vote would correspond to a point located on the vertex. Thus, roughly speaking, as we move away from the CDU vertex, the vote shares of CDU candidates decrease while vote shares of SPD or other candidates increase. To highlight the areas in which a party's candidate wins a plurality of the vote, dashed lines are drawn into the plots. They divide each diagram into three kite-shaped regions, which we shall refer to as win regions. All constituencies falling into one of these areas are won by the candidate of the party associated with the respective vertex, e.g. a constituency falling into the lower right area in the left-hand graph in Fig. 1 is won by the
CDU candidate. If two candidates obtain equal vote shares, the respective outcome is located on one of the dashed lines, e.g. if CDU and SPD candidates are tied for first place, the respective district outcome lies somewhere on the vertical line perpendicular to the bottom edge of the triangle. At the intersection of the lines of ties - the centroid of the triangle - all three parties obtain one-third of the vote. Finally, note that differences in the overall number of constituencies between 1998 and later elections are due to a reduction in parliamentary seats, which led to redistricting and the resolution of 29 constituencies between 1998 and 2002.

Inspecting Figs. 1-3, it is apparent that East and West German constituencies differ from each other. West German districts are obviously characterized by two-party competition between candidates of CDU and SPD, as can be seen from the left-hand diagrams in each figure. Other candidates play virtually no role, since, even when combining their vote shares, results are still located at clear distance from the center. By 
+ MODEL
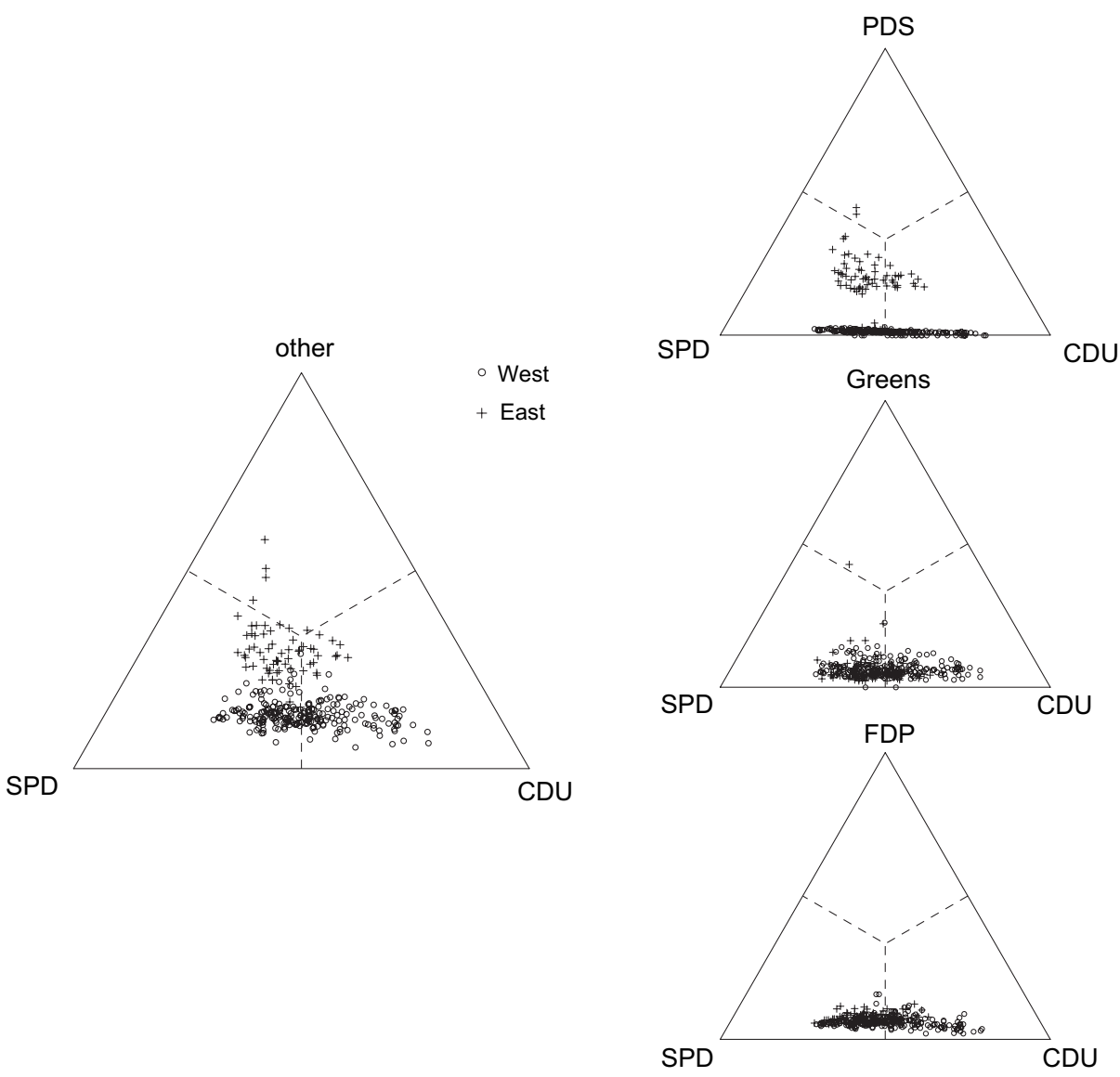

Fig. 2. Constituency results in $2002(N=299)$.

contrast, East German districts show a much larger share of votes for third party candidates, which draws those constituencies closer to the center of the triangle. ${ }^{5}$ This pattern may be due to a generally weaker performance of CDU and SPD candidates in East Germany, but it may also arise from a particularly better performance of certain third party candidates there.

To get to these specifics, we turn to the right-hand side diagrams, which give the distribution of results for East and West German constituencies stratified by the three small parties PDS, Greens and FDP. We can see that CDU and SPD candidates do not lose votes equally to small party candidates in East Germany, but particularly to candidates of PDS. In each of the three elections, those candidates win a substantially larger fraction of votes than their FDP and Greens counterparts. They even manage to win some constituencies

\footnotetext{
${ }^{5}$ Note that there is one constituency in 1998 (Fürstenwalde-Strausberg-Seelow) where the CDU failed to field a candidate. The respective outcome is therefore located on the edge of the triangle.
}

or finish second after SPD in others (in 2005, they also finish second after CDU in some constituencies). ${ }^{6} \mathrm{Be}-$ sides, there is also one exceptionally strong Green candidate, Christian Stroebele, who finished second in 1998 and managed to win his constituency (Berlin-Friedrichshain-Kreuzberg) in 2002 and 2005. Comparing elections over time, outcomes in 2005 appear somewhat

\footnotetext{
${ }^{6}$ Constituencies where PDS candidates finish second are those inside SPD's or CDU's win region that lie closer to the line of ties between SPD and PDS - or CDU and PDS, respectively - than to the line of ties between CDU and SPD. The order of finish between CDU, SPD and PDS candidates can generally be inferred by bisecting each win region into two right-angled triangles, each containing districts in which the party whose associated win region is adjacent to the triangle finishes second (see Miller, 1977; Grofman et al., 2004). For instance, bisecting the win region associated with the SPD candidate yields an upper triangle, adjacent to the PDS candidate's win region, and a lower triangle adjacent to the CDU candidate's win region. Hence the PDS candidate finishes second after SPD in districts falling into the upper triangle and the CDU candidate finishes second after SPD in districts falling into the lower triangle. The same logic applies with respect to districts won by CDU or PDS candidates.
} 

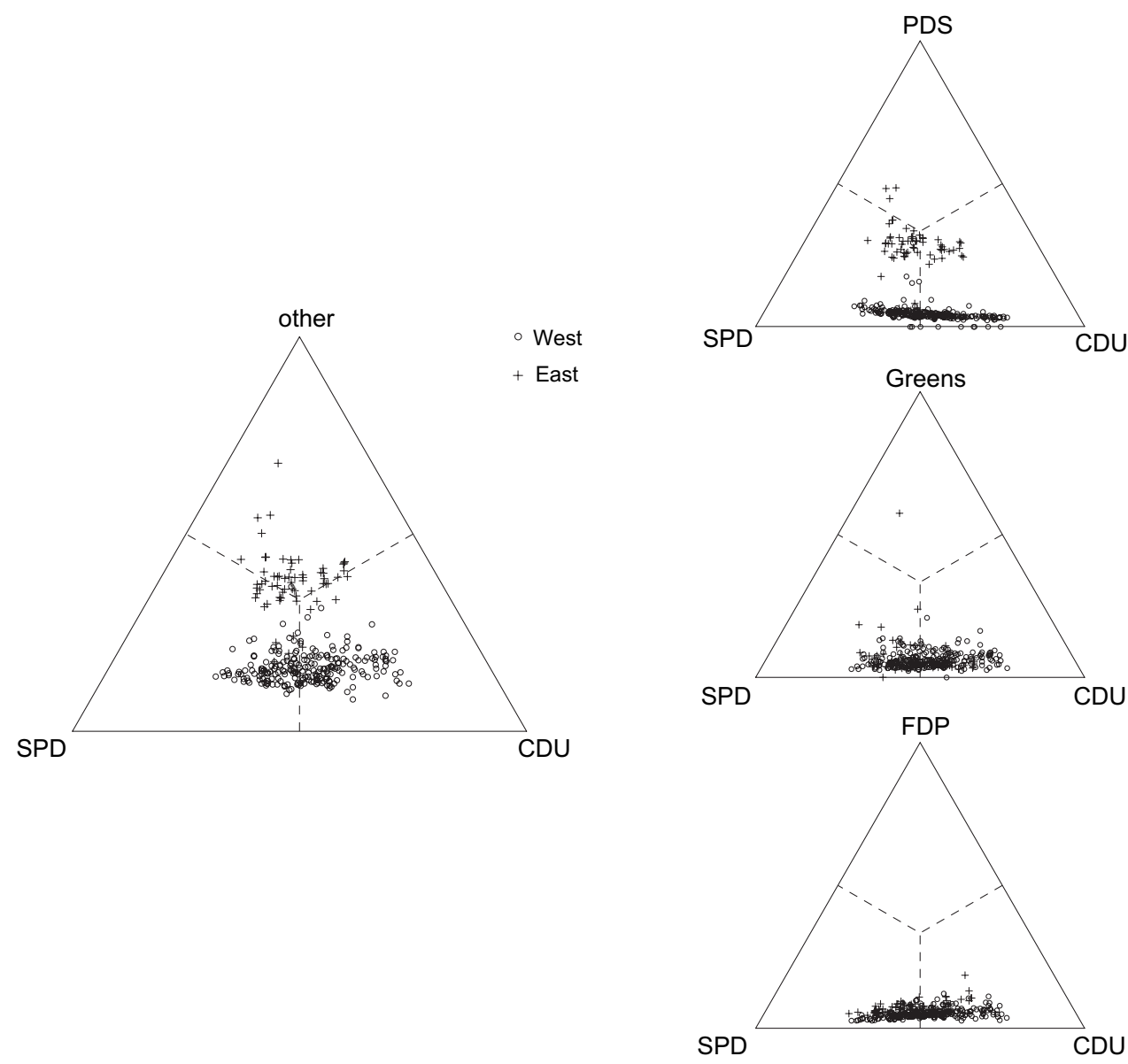

Fig. 3. Constituency results in $2005(N=299)$.

more clustered around the point of a three-way tie than those in 1998 and 2002.

Overall, East German constituencies exhibit more heterogeneity than West German constituencies. In some districts SPD and CDU candidates finish first and second, in others candidates of SPD and PDS assume the top two positions, and yet in some districts candidates of CDU, SPD and PDS all obtain about equal shares of votes. Also, in a race between CDU, SPD and PDS, the candidate finishing third is never trailing as much as they would under West German conditions, where candidates of the two large parties win the lion's share of the vote. The conclusion we draw from this observation is that the electoral environment in East Germany generally features three viable candidates as opposed to only two in West Germany. Therefore, the clear-cut distinction between large parties and small parties, which is commonly assumed in the literature does not readily extend to East German constituencies, where PDS candidates successfully compete against those of CDU and SPD. An appropriate model of strategic voting has to take the role of PDS seriously and account for these differences in the electoral environment. Such a model is now laid out.

\section{Model and hypotheses}

In this section, we outline the model that allows us to test for strategic voting in German constituencies. Throughout the analysis we maintain the assumption that voters' support for the various candidates is guided by their party preferences. This assumption is critical for our research strategy and while we are not the first to make this assumption we cannot offer an improvement over prior attempts in this respect. ${ }^{7}$ Still we believe it is a reasonable assumption. Intuitively, we

\footnotetext{
${ }^{7}$ In fact all the studies cited in Section 2 hinge on the assumption that candidates and their electoral prospects can be distinguished on the basis of party membership.
} 
assume that voters care about whether their constituency is represented by a candidate of one or another party (say CDU or SPD). Of course, in real world elections one would expect candidate support to depend on other factors as well, e.g. candidate personality, incumbency status, or campaign spending. Ideally, one would control for all these factors in an empirical analysis, but this was not feasible with the available data. ${ }^{8}$

More importantly, there is a rationale for believing that party preferences are the main driving force behind strategic candidate votes: After all, even a voter who is completely ignorant towards the candidates themselves can easily infer their party membership from the ballot on election day, as candidates are explicitly labeled and placed next to their party's position on the PR ballot. Given that the voter has some idea about the support levels of the parties in her constituency, she can also deduce candidates' likely support levels from their party membership. Party membership thus provides a common frame of reference for voters and might serve as a benchmark for evaluating candidates along with their relative support levels in the constituency. It is for that reason, we believe, that if there is strategic voting in German constituencies we would expect to find it along partisan lines.

To model strategic voting, we take a decisiontheoretic approach. Specifically, we employ the calculus of voting concept for multi-candidate elections (McKelvey and Ordeshook, 1972), which is used in formal models of strategic voting (Palfrey, 1989; Myerson and Weber, 1993; Cox, 1994; Myatt, 2007) as well as in a number of empirical studies (Black, 1978; Cain, 1978; Ordeshook and Zeng, 1997; Fisher, 2004). The main reason we take this approach is that it allows us to capture the full extent of strategic voting in East and West German constituencies alike. Being a general theoretical concept, the multi-candidate calculus of voting is supposed to be applicable to any kind of plurality election involving three or more candidates. Moreover, testing for strategic voting with this model, at the same time, yields some insights into the applicability of formal voting theory to the German case. Apart from that, we believe that an approach closely guided by theory is most likely to produce unbiased and reliable estimates of strategic voting (cf. Alvarez and Nagler, 2000, 63-64). Hence, to us, it appears as the most promising avenue to start from.

\footnotetext{
${ }^{8}$ Given these limitations, the results we obtain need to be interpreted against the backdrop of potential confounding factors (see Section 4.1).
}

To begin with, consider the following expression for the expected utility gain of voting for candidate $i$ :

$G_{i}=\sum_{j \neq i} p_{i j}\left(U_{i}-U_{j}\right)$

Myerson and Weber $(1993,104)$ refer to this as voters' prospective rating of candidate $i$ (see also McKelvey and Ordeshook, 1972; Black, 1978; Hoffman, 1982; Cox, 1994). Intuitively this equation can be interpreted as a series of pairwise comparisons between candidate $i$ and all other candidates $j$, where $p_{i j}$ denotes the probability that someone's vote is decisive in changing the winner of the election from $j$ to $i$, and $U_{i}-U_{j}$ denotes the utility gain derived from this event. ${ }^{9}$ If we label the candidates according to their rank in the voter's preference ordering, then $G_{1}$ denotes the expected utility gain of voting for one's most preferred candidate, $G_{2}$ the expected utility gain of voting second preference, and so on. A voter is assumed to choose the candidate $i$ that maximizes her expected utility gain, i.e. to vote for the candidate $i$ whose associated value $G_{i}$ is greater than the $G_{j}$ associated with a vote for any other candidate $j$. Accordingly we can define a vote for the top ranked candidate as sincere and a vote for the candidate ranked second as strategic.

In doing so, we a priori exclude the possibility of voting for a candidate ranked third or lower. Even though it would, in principle, be possible to stipulate a model that would allow for third and fourth preference voting, the restriction to a binary choice is mainly done with regard to the fact that preference orderings with non-viable candidates on the first two (or three) ranks are very rare. Employing a polychotomous choice model would thus hardly yield meaningful estimates of third and fourth preference voting.

Note further that the definition of a second preference vote as strategic excludes other reasons for second preference voting, such as personal votes for popular candidates from parties other than the most preferred one. While such alternative motivations can be safely ignored in a theoretical model of purely instrumental voting, their empirical presence may entail measurement error in the actual identification of strategic voters (an issue to which we shall come back in the discussion of our results).

\footnotetext{
${ }^{9}$ Following McKelvey and Ordeshook (1972) and Myerson and Weber (1993) we assume that the probability of being decisive between three or more candidates is negligibly small compared to the probability of being decisive between two candidates, hence the probabilities of ties between three or more parties are considered zero.
} 
Restricting attention to first vs. second preference voting, a voter is assumed to face a dichotomous choice and to vote sincerely, whenever the expected gain of voting first preference exceeds that of voting second preference. This means she is assumed to vote sincerely if $G_{1}-G_{2}>0$ and strategically if $G_{1}-G_{2}<0$, where

$G_{1}-G_{2}=\sum_{j \neq 1} p_{1 j} B_{1 j}-\sum_{j \neq 2} p_{2 j} B_{2 j}$

For simplicity, the utility differentials are denoted shorthand as $B_{1 j}=U_{1}-U_{j}$ and $B_{2 j}=U_{2}-U_{j}$. $B_{2 j}$ thus denotes the utility gain derived from changing the election result from a victory of one's $j$ th preferencewhere candidate $j$ is ranked third or lower- to a victory of one's second preference. Likewise $p_{2 j}$ denotes the probability of being pivotal in a race between one's second and $j$ th preferred candidate. As can be seen, larger $p_{1 j} B_{1 j}$ terms influence individual decision making in favor of sincere (first preference) voting, while larger $p_{2 j} B_{2 j}$ terms influence individual decision making in favor of strategic (second preference) voting.

To give a simple example, consider the typical situation of an individual voter in a West German district. The voter might prefer the candidate of the Green party who is running very poorly in her electoral district. Her third and fifth preferred candidates also have little chance of winning the constituency, but the race is close between her second and fourth preference, i.e. the candidates of SPD and CDU. Hence $p_{24}$ should be large, compared to the other pivot probabilities $p_{12}, p_{13}, p_{14}$, $p_{15} p_{23}$, and $p_{25}$. Thus from the perspective of influencing the election result that voter should have a strong tendency to vote for her second preference, SPD, in order to prevent the victory of the less preferred CDU candidate. Note that this tendency is the more pronounced, the larger $B_{24}$, i.e. the more she prefers the SPD candidate over the CDU candidate. Conversely, her incentive to desert the Green candidate is the weaker the larger $B_{12}$, i.e. the more she favors the Green candidate over the SPD candidate.

As we have seen in the previous section, the scenario just described is quite typical for supporters of Green party candidates in West German districts (and also for supporters of FDP and PDS candidates). Indeed, the fact that candidate support is distributed highly unequal across parties and across East and West German districts allows us to simplify the above decision calculus, by ruling out a number of constellations voters are unlikely to face in their electoral district. For instance, a West German voter supporting the candidate of CDU should have no reason to deliberate about scenarios in which her vote will be decisive in a race between her preferred candidate and any other but the SPD candidate. All other candidates can be considered marginal in the race for first place. It should also be of little importance how likely she is to influence a race for first place between her second preference and a lesser preferred candidate, because the CDU candidate is always a viable option.

On the other hand, deciding whether to vote sincerely or not, supporters of FDP, PDS and Green candidates should be sensitive to the closeness of the race between the candidates of CDU and SPD, as long as they hold a second preference for one of them. Since their expectations of being decisive between their first preference and any other candidate in the constituency are negligibly small, their decision should instead be driven by the perception of being decisive between CDU and SPD. Hence, upon deciding whether to cast a sincere or strategic vote, any consideration of being decisive between some pair of candidates from parties other than CDU and SPD should be irrelevant for a West German voter, as the chances of being decisive between any other combination (e.g. CDU vs. FDP, SPD vs. PDS, or FDP vs. Greens) are minuscule, compared to the chances of influencing the race between CDU and SPD.

We can introduce this feature of West German constituencies into the decision calculus in Eq. (2) by setting $p_{1 j}=0$ and/or $p_{2 j}=0$ in Eq. (2), for all comparisons involving candidates from either FDP, Greens or PDS. Thus, for West German constituencies, we consider only candidates of CDU and SPD as viable options. Depending on voters' preference orderings, this leads us to distinguish three types (or classes) of voters, which are displayed in Table $1 .^{10}$

To see how the introduction of non-viability narrows down the decision calculus, consider a Type 1 voter. This voter's preference profile starts either with a CDU candidate on first and SPD candidate on second rank or the other way around. Other (non-viable) candidates receive lower ranks. The voter's expected gain of voting first preference reduces to $G_{1}=p_{12} B_{12}$, i.e. the gain derived from being pivotal in a race between first and second preference. All other terms drop out, due to their associated zero probabilities. In a similar fashion, the expected gain of voting second preference

\footnotetext{
${ }^{10}$ Note that voters must hold at least one viable candidate on either first or second rank. For voters holding first and second preferences for candidates of (non-viable) small parties the $p$ terms are irrelevant as the chances of getting their first or second preference elected are both equally small.
} 
Table 1

Voter types for West Germany

\begin{tabular}{lll}
\hline Voter type & Preference profile $(1 \mathrm{st}, 2 \mathrm{nd}, \ldots, k$ th, $\ldots)$ & $G_{1}-G_{2}$ \\
\hline Type 1 & Viable $>$ viable $>\cdots$ & $2 p_{12} B_{12}$ \\
Type 2 & Viable $>$ non-viable $>\cdots>$ viable $>\cdots$ & $p_{1 k} B_{1 k}$ \\
Type 3 & Non-viable $>$ viable $>\cdots>$ viable $>\cdots$ & $-p_{2 k} B_{2 k}$ \\
\hline
\end{tabular}

Set of viable candidates, $\{\mathrm{CDU}, \mathrm{SPD}\}$; set of non-viable candidates, $\{$ FDP, Greens, PDS $\} ; \cdots$ indicates a series of (one or more) non-viable candidates.

reduces to $G_{2}=p_{21} B_{21}$, which is the gain derived from turning one's second preference into the winneras opposed to one's first preference. Thus, for a Type 1 voter, $G_{1}-G_{2}$ reduces to $p_{12} B_{12}-p_{21} B_{21}$, which can be further simplified to $2 p_{12} B_{12}$, since $B_{12}=-B_{21}$ and $p_{12}=p_{21}$, i.e. the probability of being pivotal between one's first and second preference is also the probability of being decisive between one's second and first preference (McKelvey and Ordeshook, 1972; Myerson and Weber, 1993). Likewise, for Type 2 voters the introduction of zero probabilities for being pivotal results in $G_{2}=0$ and $G_{1}=p_{1 k} B_{1 k}$, where $k$ indexes the preference rank of the other viable party, ranked either third, fourth or fifth. A similar, although reversed, logic applies for Type 3 voters. As can be seen from Table 1, the expected utility differential $G_{1}-G_{1}$ is only negative for Type 3 voters, who hold a first preference for a candidate from a non-viable party (FDP, PDS or Greens) and a second preference for a candidate from a viable party (SPD or CDU). Hence, only this group of voters has an incentive to vote strategically. All other voters holding a first preference for a viable party should vote sincerely.

For East German constituencies, the number of viable candidates there is roughly three, includingbesides candidates from CDU and SPD-also candidates of PDS (see Section 2). As in the West German context, candidates of FDP and Greens can be considered non-viable. Thus we assume $p_{1 j}=0$ and $p_{2 j}=0$ for every comparison involving either a candidate of FDP or Greens. Depending on voter's preference orderings, this leads to four different types of expected utility differentials, which are displayed in Table 2.

As can be seen, the first three types of voters are the same as for the West German context, but due to three instead of two viable parties one new type is generated. This category is comprised of voters holding two viable candidates on first and second and a third one on a lower preference rank. For these voters the decision to vote strategically involves comparisons of the most preferred candidate with the other two, as well as a comparison between the candidate ranked second and the least preferred viable candidate. Therefore, in contrast to voters of Types $1-3$, Type 4 voters have both an incentive to vote sincerely as well as strategically.

To give an example, consider a PDS supporter with second preference SPD, Greens on third, CDU on fourth and FDP on fifth rank, who finds herself in a constituency, where the PDS candidate is runner-up behind SPD and the CDU candidate comes on third. Her decision is one between PDS, SPD and CDU, since Greens and FDP are irrelevant for the outcome of the constituency election. When comparing the options of voting for PDS or voting for SPD, she finds that the expected gain of a sincere vote is higher than that of a strategic vote, as the chances of influencing the election outcome between PDS and SPD $\left(p_{12}\right)$ are higher than the chances of being decisive in a race between PDS and CDU $\left(p_{1 k}\right)$ or SPD and CDU $\left(p_{2 k}\right)$. Her incentive to vote sincerely should be even more pronounced the more she favors PDS over SPD, i.e. the larger $B_{12}$ is.

Now consider the same voter in a district, where the PDS candidate comes third behind SPD and the leading CDU candidate. Her chances of being pivotal in making the PDS candidate the winner of the election (either against SPD or CDU) are now small compared to the chances of being decisive between her second and third preference SPD and CDU. The closer those two candidates are together (i.e. the higher $p_{2 k}$ ) and the more she favors SPD over CDU (i.e. the higher $B_{2 k}$ ), the more likely she should be to desert her first preference and cast a strategic vote for the SPD candidate. Therefore,

Table 2

Voter types for East Germany

\begin{tabular}{lll}
\hline Voter type & Preference profile $(1$ st, 2 nd, $, \ldots, k$ th,,$\ldots)$ & $G_{1}-G_{2}$ \\
\hline Type 1 & Viable $>$ viable $>\cdots>$ non-viable & $2 p_{12} B_{12}$ \\
Type 2 & Viable $>$ non-viable $>\cdots>$ viable $>\cdots$ & $p_{1 k} B_{1 k}$ \\
Type 3 & Non-viable $>$ viable $>\cdots>$ viable $>\cdots$ & $-p_{2 k} B_{2 k}$ \\
Type 4 & Viable $>$ viable $>\cdots>$ viable $>\cdots$ & $2 p_{12} B_{12}+p_{1 k} B_{1 k}-p_{2 k} B_{2 k}$
\end{tabular}

Set of viable candidates, \{CDU, SPD, PDS \}; set of non-viable candidates, \{FDP, Greens\}; $>\cdots>$ indicates a series of (one or more) non-viable candidates; $>\cdots$ indicates a series of (one or more) viable or non-viable candidates. 
for a Type 4 voter we cannot rule out a priori the possibility of a strategic vote. Rather, her incentive to vote strategically should increase with $p_{2 k} B_{2 k}$, while her incentive to vote sincerely should increase with $p_{12} B_{12}$ and $p_{1 k} B_{1 k}$.

Assembling the terms from Tables 1 and 2, we can formulate the following empirical model for strategic voting. Define the outcome variable as $Y=1$ if someone votes for her first and $Y=0$ if she votes for her second preference, then the probability of observing a sincere as opposed to a strategic vote can be expressed with a probit model: ${ }^{11}$

$$
\begin{aligned}
\operatorname{Pr}(Y=1)= & \Phi\left(\alpha+\beta_{1} P_{12} B_{12}+\beta_{2} P_{1 k} B_{1 k}+\beta_{3} P_{2 k} B_{2 k}\right. \\
& \left.+\gamma_{t} \mathrm{TYPE}_{t}\right)
\end{aligned}
$$

The term $\alpha$ denotes an overall constant, indicating the baseline amount of sincere voting. One may think of this coefficient as capturing the effect of other unmeasured factors that might lead a voter to cast a sincere vote, e.g. candidate preference, party identification, etc. $\mathrm{TYPE}_{t}$ denotes a (row)vector of $t$ dummy variables with associated coefficients $\gamma_{t}$. Each dummy variable scores 1 if the voter is of type $t$ (e.g. Type 3), otherwise zero. This means that if, for instance, $t=2$ the variables $P_{12} B_{12}$ and $P_{2 k} B_{2 k}$ are zero. The coefficients $\gamma_{t}$ capture differences in the average amount of sincere voting between the individual voter types. Our expectations concerning these differences are as follows:

1. Type 2 voters, holding a viable party on first and a non-viable party on second rank, should have the highest coefficient, i.e. the highest probability of a sincere vote, since they have the chance of being decisive between their first and a much less preferred alternative.

2. Type 1 voters should have a lower coefficient than Type 2 voters, since they can only be decisive between first and second preference, i.e. their expected gain is somewhat lower.

3 . Type 4 voters have incentives to vote both sincerely and strategically, hence their coefficient should be lower than that of Type 1 voters, who have no incentive for strategic voting.

4. Type 3 voters have no incentive to vote sincerely, hence their coefficient should be lowest.

\footnotetext{
11 The factor 2 from $2 p_{12} B_{12}$ is irrelevant to the estimation of $\beta_{1}$ and is thus dropped from Eq. (3).
}

Since these differences should fully depend on voter's strength of preference and perceived pivot probabilities, we expect them to disappear once we control for the $P B$ variables in the model. Specifically, strategic voting implies that:

5. The coefficient for $P_{2 k} B_{2 k}$ should be negative.

6. The coefficients for $P_{12} B_{12}$ and $P_{1 k} B_{1 k}$ should be positive. $^{12}$

In sum, our empirical model captures the notion commonly found in the literature that West German supporters of CDU or SPD should vote sincerely, whereas supporters of FDP, Greens and PDS have an incentive to defect from their first preference, but it goes beyond that by also accounting for situations where the order of finish between winner and first loser on the district level is determined by three parties, CDU, SPD and PDS, which is generally the case in East German districts. Furthermore we focus not only on voter expectations but on their relative preferences as well, since theoretically, they are equally important for the decision to vote strategically.

At this point, the question may arise why the restrictions on pivot probabilities are introduced at all, since Eq. (2) could be used as an empirical model right away. There are two main reasons not to use Eq. (2) directly, one practical and the other substantive. From a practical point of view, estimating the entire calculus equation would lead to low cell frequencies and a poor estimation of the effects of $p_{24} B_{24}$ and $p_{25} B_{25}$. Since longer preference rankings are less likely than shorter ones, we expect less observations for $p_{24} B_{24}$ than for $p_{23} B_{23}$ and even less for $p_{25} B_{25}$. However, for the decision to vote strategically one term may be just as relevant as the other. In fact, as we have seen above, which term is in fact relevant depends-for most

\footnotetext{
${ }_{12}$ In Eq. (3) there are no main effects for variables $P_{1 k} B_{i k}$. It is common practice to include main effects when testing for interactions so that one variable can still have an effect if the other variable is zero. In our case the $P$ and $B$ variables are constructed in such a way that a value of zero on one variable theoretically implies a value of zeroand hence no effect-of the other variable (see Section 3.1); it is thus meaningful to use the $P B$ terms alone (see also Ordeshook and Zeng, 1997, 173). Likelihood ratio tests also confirmed that the inclusion of main effects did not improve the fit of the model, nor did the inclusion of interaction effects improve the fit of a main effects model Model comparisons on the basis of Bayesian information criterion (and other goodness-of-fit measures that adjust for unequal degrees of freedom) further confirmed that our version of the model should be preferred over both, a simple additive main effects model, as well as a main effects model with interaction terms (results available from the authors).
} 
voters-on the placement of the CDU and SPD candidates in their preference ordering. If one candidate is ranked second and the other ranked third, $p_{23} B_{23}$ should be the decisive component; if the other is on fifth, $p_{25} B_{25}$ should make the difference. All other terms should be small (or close to zero). Likewise, for the decision to vote sincerely, it is again the placement of candidates that matters. If the CDU candidate is on first and the other viable candidate on third rank, $p_{13} B_{13}$ should make the difference; if the other candidate is on fourth rank, it should be $p_{14} B_{14}$. Our approach is to simply pool all relevant terms into two components $p_{2 k} B_{2 k}$ and $p_{1 k} B_{1 k}$, which can be effectively estimated with the available data.

Substantively, we can also learn more about likely strategic voters through the categorization into the voter types given above. Specifically, it allows us to distinguish between strategic voting by supporters of candidates that are sure losers in constituency races (Type 3 ), and by those (slightly more interesting voters) who support one of three potentially viable candidates in East German constituencies (Type 4). This would not be possible from a direct implementation of Eq. (2), which basically lumps together supporters of all candidates. Overall, our distinction of four voter types thus makes the analysis both tractable and easier to interpret.

\subsection{Data and measurement}

We use data from two national pre-election surveys conducted in $1998(N=1608)$ and $2002(N=1632) .{ }^{13}$ A similar survey was also administered in 2005 , however, by the time we conducted our analysis the data were not yet available. Voters' preference rankings were constructed from party feeling thermometers (see Appendix A. 2 for the wording of the thermometer question). ${ }^{14}$ Based on those rankings, we identified respondents as belonging to one of the four voter types introduced above. From all respondents who provided non-missing information on their voting decision and (at least three) thermometer ratings (roughly $72 \%$ in both samples), respondents whose preference rankings did not match one of the four types were excluded

\footnotetext{
${ }^{13}$ Both surveys were part of the project 'Politische Einstellungen, politische Partizipation und Wählerverhalten im vereinigten Deutschland', conducted by Jürgen Falter, Oscar Gabriel and Hans Rattinger. Datasets can be obtained from 'Central Archive for Empirical Social Research' at http://www.gesis.org/en/za; Archive no: ZA 3066 and ZA 3861.

${ }^{14}$ For Bavarian respondents feeling thermometers towards CSU were employed in place of CDU thermometers.
}

from the analysis. ${ }^{15}$ The dependent variable is coded as 1 if a respondent reported to vote for a party he ranked first (sincere vote) and 0 if he reported voting for a party he ranked second (strategic vote). Respondents who reported to vote for a party they ranked third or lower were not considered for the analysis. ${ }^{16}$ Overall $52 \%$ of the respondents in the 1998 and 50\% in the 2002 sample were identified as Type 1,2,3 or 4 voters who report voting for either first (roughly 90\% in both samples) or second preference (roughly 10\%). This group comprises the final sample for the analysis.

Voters' relative preferences for the candidates of each party were computed as differences in standardized party thermometer scores. Formally, for each individual voter the standardized thermometer differences were computed as $B_{i j}=\left(b_{i}-b_{j}\right) / \sigma$, where $b_{i}$ and $b_{j}$ are the raw thermometer values assigned to candidates $i$ and $j$ and $\sigma$ is the standard deviation of thermometer scores assigned by the individual voter. Standardization ensures that variation in variables $B_{i j}$ is solely due to intra-individual differences in the assignment of thermometer scores. Different voters might have different interpretations about the scaling of their response. Thus a voter who assigns to candidates the values 3, 5 and 7 on a scale from 1 to 11 , might well have the same in mind as a voter who assigns to them the values 8, 9 and 10 (with the order of candidates being the same). Based on raw thermometer scores we would conclude that the first voter holds stronger preferences between candidates than the second voter. On the other hand, it is just as possible that both voters feel equally strong about the candidates and simply hold different perceptions as to how their preferences translate into the response format. Ultimately there is no standard for comparing utility differences inter-individually, therefore we considered it worthwhile to attenuate variation in utility judgments between individuals. That is to say we place more weight on variation in utility

\footnotetext{
$\overline{15}$ For instance, respondents with two or more parties tied for first rank were excluded from the analysis. Likewise, respondents with no third preference (i.e. all parties other than first rank are tied for second preference) were not considered. Respondents with first and second preferences for non-viable parties were excluded as well. In one way or another, our model yields no prediction for any of these respondents, i.e. we cannot formulate hypotheses as to whether they should vote for first or second preference.

${ }^{16}$ While it is possible, in principle, for such behavior to qualify as strategic, i.e. voting for someone's third preference to avoid the success of a lesser preferred alternative, if one's first and second preference are non-viable, we restrict our attention to strategic second preference voting. In addition, a preliminary investigation showed that the number of voters voting for a candidate ranked third or lower is very small (about $3 \%$ in both samples).
} 
differentials within voters than between voters. After standardization the two voters above, for example, would both be assigned thermometer differences of about 1.225 .

For the measurement of voter pivotality, we follow Black (1978) who calculates decisiveness as Euclidian distances of constituency results to outcomes in which a voter would have been decisive in determining the winner. ${ }^{17}$ To give an example, consider an East German district in which PDS, SPD and CDU candidates obtain shares of $0.40,0.36$ and 0.24 , respectively, and a voter who ranks the candidates in the same order. The three quantities of interest in this case are the probabilities of a tie for the lead between PDS and SPD (i.e. $P_{12}$ ), PDS and CDU (i.e. $P_{13}$ ), and SPD and CDU (i.e. $P_{23}$ ). A measure for the probability of being decisive between PDS and SPD can be obtained by calculating the distance between the outcome $(0.40,0.36,0.24)$ and the closest outcome in which the voter would have been pivotal, i.e. $(0.38,0.38,0.24)$. The Euclidian distance between the two outcomes is calculated as $\left[(0.40-0.38)^{2}+(0.36-0.38)^{2}+(0.24-0.24)^{2}\right]^{1 / 2}=$ 0.028 . Dividing this quantity by the distance that can maximally be obtained and subtracting from one yields a proxy for the pivot probability that ranges from zero (when one party wins the entire vote) to one (when two parties are tied for first place). Other measures of decisiveness can be calculated in a similar way (for a more detailed explanation of this procedure, see Appendix A.1 or Black, 1978, 634ff.).

\section{Results}

The results of our model estimations for the 1998 and 2002 elections, respectively, are given in Table 3. For each election year, the left-hand columns display the results for the restricted models, including only the indicator variables for the different voter types, and the right-hand columns give the results for the full model including the $P B$ terms. We use one-tailed tests for evaluating our results, since we are interested in whether coefficients point significantly in the

\footnotetext{
17 To compute distances, we used constituency results of the current election. Some scholars prefer to use results of the previous election (e.g. Alvarez and Nagler, 2000). We believe that current election results more closely resemble the situation in electoral districts at the time survey data were collected. Hence we expect them to better approximate voter's expectations than results from previous elections. Apart from that, due to federal redistricting between 1998 and 2002 constituency results in 1998 could not be matched with those in 2002 .
}

hypothesized directions, rather than testing for nonzero effects in any direction.

Our first set of hypotheses concerned differences between the four voter types identified in Section 3. Accordingly, Type 2 voters should show the highest tendency for sincere voting, followed by Type 1, Type 4 and Type 3 voters. As can be seen from Table 3, all group effects follow the predicted order. In both elections, Type 2 voters (the reference group, with coefficient fixed at zero) have the highest propensity to cast a sincere vote followed by Type 1, Type 4 and Type 3 voters. All differences, except for Type 1 voters in 2002 are statistically significant $(p<0.05)$. As expected, Type 3 voters show the highest propensity to vote strategically, since they find themselves unanimously in a situation where their most preferred candidate is out of the race. Concerning our third hypothesis, the difference between Type 4 and Type 1 votersalbeit in the right direction-does not reach statistical significance. Thus, although there is potential for strategic voting among Type 4 voters it does not suffice to distinguish them from voters whose first and second preference are both viable options in the constituency. It does, however, distinguish them from the other, more motivated, group of (Type 2) sincere voters whose most preferred candidate is competing against a candidate ranked third or lower. Overall, while some of the group effects could be more pronounced none of the coefficients is at odds with our expectations and most differences are statistically significant.

Concerning the second set of hypotheses, we have argued in Section 3, that differences between voter types should be determined by voters' relative preferences and perceived pivotality. Hence differences between voter types should disappear once we control for voter preferences and expectations. According to our theoretical model, we also expect a positive sign on the coefficients for variables $P_{12} B_{12}$ and $P_{1 k} B_{1 k}$ and a negative sign on the coefficient for $P_{2 k} B_{2 k}$. As can be seen from the right-hand columns, all the coefficients for the individual groups-except for Type 4 voters in 1998 - markedly shrink once the $P B$ variables are introduced. On the other hand, all $P B$ coefficients are correctly signed and most of them are statistically significant $(p<0.05)$. The effects for $P_{12} B_{12}$ are not significant, indicating that being decisive and having a strong relative preference between one's first and second preference does not create much of an incentive for sincere voting. A significant incentive for sincere voting exists, however, if one of the two viable options is on third or lower preference, as indicated by the effect of $P_{1 k} B_{1 k}$. 
+ MODEL

Table 3

Sincere vs. strategic voting: probit regression results

\begin{tabular}{|c|c|c|c|c|}
\hline & 1998 & & 2002 & \\
\hline Type $1^{\mathrm{a}}$ & $-0.476(0.196)^{b}$ & $-0.107(0.512)$ & $-0.242(0.172)$ & $0.187(0.344)$ \\
\hline Type $3^{\mathrm{a}}$ & $-2.037(0.196)^{b}$ & $-0.789(0.507)$ & $-1.335(0.160)^{\mathrm{b}}$ & $-0.166(0.407)$ \\
\hline Type $4^{\mathrm{a}}$ & $-0.671(0.203)^{\mathrm{b}}$ & $-0.825(0.433)^{\mathrm{b}}$ & $-0.651(0.173)^{\mathrm{b}}$ & $-0.093(0.419)$ \\
\hline$P_{12} B_{12}$ & & $0.601(0.367)$ & & $0.050(0.161)$ \\
\hline$P_{1 k} B_{1 k}$ & & $0.534(0.229)^{\mathrm{b}}$ & & $0.314(0.175)^{b}$ \\
\hline$P_{2 k} B_{2 k}$ & & $-0.369(0.203)^{\mathrm{b}}$ & & $-0.623(0.197)^{b}$ \\
\hline Const. & $2.024(0.146)^{\mathrm{b}}$ & $1.190(0.366)^{\mathrm{b}}$ & $1.668(0.105)^{\mathrm{b}}$ & $1.199(0.274)^{b}$ \\
\hline $\mathrm{LL}_{0}$ & -269.872 & -269.872 & -293.927 & -293.927 \\
\hline $\mathrm{LL}_{1}$ & -201.834 & -194.894 & -255.807 & -248.974 \\
\hline$N$ & \multicolumn{2}{|c|}{852} & \multicolumn{2}{|c|}{836} \\
\hline
\end{tabular}

${ }^{\text {a }}$ Coefficients for Type 2 voters fixed at zero; for explanation of types, see Tables 1 and 2.

${ }^{\mathrm{b}} p<0.05$ one-tailed. Standard errors in parentheses.

Most critical to the event of strategic voting is the term $\mathrm{P}_{2 k} \mathrm{~B}_{2 k}$. For strategic voting to be present, this variable must be negatively correlated with sincere voting. As can be seen, the coefficients for $P_{2 k} B_{2 k}$ are negative and significant for both election years, suggesting that decisiveness and a strong relative preference between one's second preference and a less preferred alternative, indeed, creates an incentive for strategic voting. In sum, the results presented here provide evidence that German voters cast their constituency vote strategically, depending on their preferences and perceived chances of influencing the election outcome. Specifically, the more a voter favors her second preference over a lower ranked viable candidate and the closer the race between the two in her district, the higher the probability that she casts a strategic vote.

Fig. 4 displays this relationship graphically for voters with different levels of relative preference $\left(B_{2 k}\right)$. The vertical axis indicates the probability of casting a sincere vote, the horizontal axis indicates voters' pivotality in deciding between their second and $k$ th preference $\left(P_{2 k}\right)$. In the upper panels of Fig. 4 the relationship is given for Type 3 voters holding a first preference for a candidate of a non-viable party and a second preference for a candidate of a viable party. By design, this group is comprised by supporters of FDP, Green and PDS candidates in West Germany and supporters of FDP and Green candidates in East Germany. Those voters were hypothesized to vote strategically, with increasing pivot probability and increasing strength of preference, i.e. dislike of a lesser preferred viable candidate. Note that, for Type 3 voters, the impact on the election outcome is always measured as one minus the absolute difference in vote shares between the two largest parties in the district (see Appendix A), so one can interpret the horizontal axis as the reverse of the district margin. An ostensive interpretation of the upper panels of Fig. 4 would hence be that the closer the district margin, the higher the probability of FDP and Green supporters (and PDS supporters in West Germany) to vote strategically. This relationship is even more pronounced, the more such a voter disfavors the winning candidate over the second finisher. For instance, the probability that a supporter of the Greens will vote for her second preference SPD is
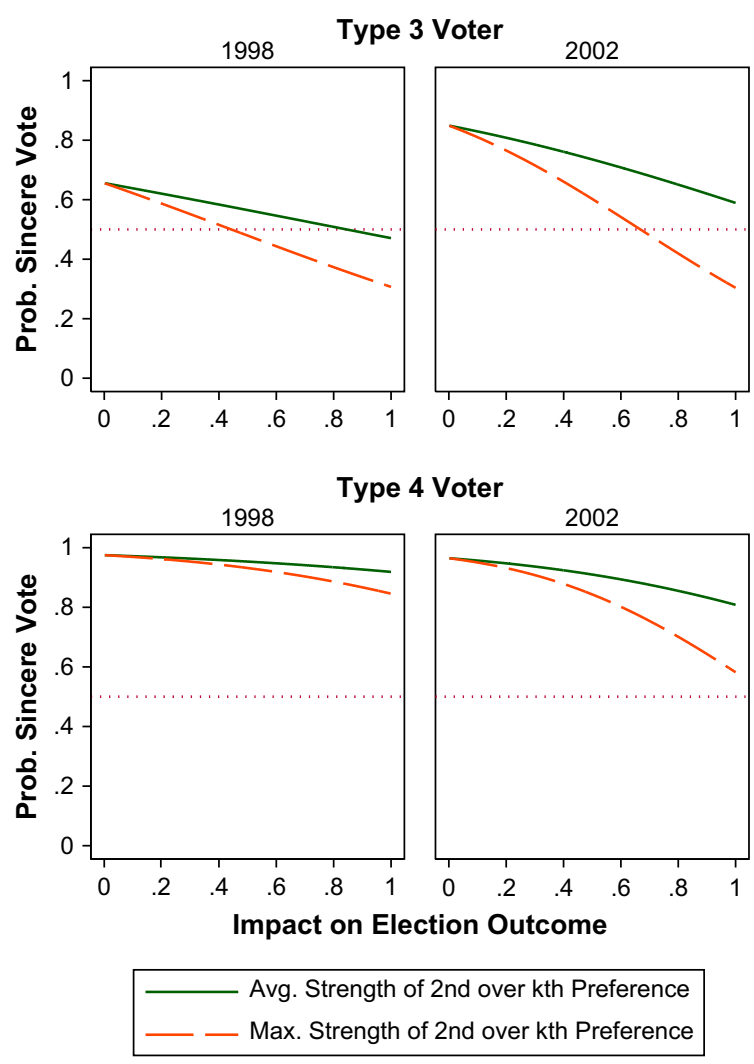

Fig. 4. Strategic voting by voter type. 
higher the closer the race between SPD and CDU and the more she favors SPD over CDU.

A similar interpretation can be given for Type 4 voters. This group is solely comprised of East German voters holding first and second preferences for candidates of CDU, SPD or PDS. Note that for this group of voters the tendency to vote strategically is less pronounced than for Type 3 voters (in 1998 the probability curve is almost flat). What can also be seen from Fig. 4 is that, overall, Type 4 voters have a higher probability to cast a sincere vote. This is due to the fact that, unlike Type 3 voters, Type 4 voters cannot $a$ priori be assumed to have an incentive to vote strategically, instead they should defect from their first preference only when it is trailing in the district race, i.e. when $p_{12}$ and $p_{1 k}$ are smaller than $p_{2 k}$. For instance, a CDU supporter with second preference SPD should vote strategically in a district where the CDU candidate comes third after SPD and PDS, or more specifically, the more the CDU candidate is trailing and the closer SPD and PDS candidates are together. In Fig. $4, P_{12} B_{12}$ and $P_{1 k} B_{1 k}$, for a Type 4 voter, are held constant at their means. Thus, the probability of a strategic vote may actually be greater than what is displayed in districts where a voter's most preferred candidate is out of the race. Finally, it also appears that the tendency to cast a strategic vote was slightly stronger in the 2002 election, as indicated by the steeper decline of the probability curves.

\subsection{The relevance of strategic voting}

Given the above results, we can ask how good our model predicts de facto voting for first or second preference. Table 4 displays the number of actual against predicted votes for both elections. Accordingly, our model correctly classifies $91 \%$ of the votes in 1998 and $89 \%$ in 2002. ${ }^{18}$

Among those predicted to cast a strategic vote, $58 \%$ and $56 \%$ actually did vote for their second preference. Ideally, we would have expected those numbers to be somewhat higher above 50\%. Our model thus does not explain second preference voting as well as we would wish. It obviously performs much better at predicting first preference voting, since $93 \%$ and $90 \%$ of those predicted to vote sincerely actually voted for their first preference. This suggests a higher amount of error in the measurement of second preference voting than first preference

\footnotetext{
18 The actual increase in correct classification due to our model is $9 \%$ and $2 \%$, respectively, compared to a prediction based on the distribution of the dependent variable alone.
}

Table 4

Actual vs. predicted votes

\begin{tabular}{lcllll}
\hline & 1998 & & & 2002 & \\
\cline { 2 - 3 } \cline { 5 - 6 } \cline { 5 - 6 } & Sincere & Strategic & & Sincere & Strategic \\
\hline Voted first & 749 & 21 & & 734 & 8 \\
Voted second & 53 & 29 & & 84 & 10 \\
Total predicted & 802 & 50 & & 818 & 18 \\
\hline
\end{tabular}

Column headers indicate predicted behavior; row headers indicate observed behavior (i.e. first vs. second preference voting).

voting and, in fact, there is reason to expect some error in observed second preference voting, as our measurement does not fully sort strategic voting out of other motivations for casting a second preference vote. For instance, we cannot rule out the possibility that some apparent second preference votes are personal votes for candidates of parties other than the preferred party. Also, we cannot identify large party supporters who perceived the constituency race as foregone and hence decided to give their vote to the sure winner (or to express their opinion on a certain issue by voting for a second preference party with a strong stand on that issue). Expressing one's preference for a certain coalition still serves as another motive for German voters in casting their ballot. Thus, a supporter of a small party (say FDP) in a non-competitive constituency may choose to express her coalition preference by casting a second preference vote for the CDU candidate and giving her PR vote to FDP.

Eventually, a good measure of strategic voting should control for voters' motivations in such a way that all reasons for a second preference vote, save for the individual's desire to effectively influence the election result, are ruled out (cf. Fisher, 2004; Blais et al., 2005). Additional questioning of voters' motivations for deserting their preferred party - the standard nowadays in British and Canadian election studies-would surely improve the measurement of strategic voting and possibly reduce some of the prediction error in classifying voters as strategic. However, no such information was available for the election surveys employed here.

From our estimates, we predict a share of roughly $6 \%$ strategic voters in the final sample for the 1998 and $2 \%$ for the 2002 election. Thus, based on the original samples and assuming that all voters not included in the final sample are non-strategic voters, we conclude that some $3 \%$ of voters in 1998 and 1\% in 2002 voted strategically. Given these numbers, strategic voting is clearly not a large scale phenomenon at German elections. Especially when compared with other published estimates of strategic voting, ranging roughly in between $5 \%$ to $17 \%$, depending on measurement (see Alvarez and Nagler, 2000, Table 1), German voters appear to be somewhat less responsive to 
electoral incentives in their local environment than voters in pure FPTP systems, such as Great Britain or Canada. But there are other possible explanations for this result.

For instance, voter preferences in Germany are highly "skewed", in the sense that there is a large bias towards CDU and SPD. Together, the two parties appear about three times as often on first preference as any other party. Hence it should be no surprise that most voters cast a sincere constituency vote for either the CDU or SPD candidate (see also Blais and Nadeau, 1996, for a very similar conclusion).

We may also underestimate the true amount of strategic voting due to our strict definition of the phenomenon. Recall that all respondents with a tied preference on first rank were excluded from the analysis. A more generous definition of strategic voting would perhaps allow for defecting one's preferred candidate in favor of a more successful but equally preferred candidate. Expanding the outcome category in such a way would certainly lead to more observed strategic behavior. Our aim was, however, to show that voters sometimes truly vote against their preferences rather than merely selecting between options of equal value.

Lastly, the extent to which voters engage in strategic voting may vary significantly between elections. For instance, Blais et al. (2001) find about $6 \%$ of strategic voting at the 1988 Canadian election but only half as much in 1997. The variability of strategic voting over longer periods of time is yet completely unexplored, so we can hardly place reliable upper and lower bounds on estimates from any single country. Thus, strictly speaking, we cannot tell whether the estimates produced here are in the upper, lower or mid-part of the distribution of strategic voting at German elections and the same caveat applies, in principle, to other strategic voting estimates. The presence of variability over time makes it hard, in general, to compare strategic voting estimates irrespective of measurement or methodology. Therefore we should not demand too much of the present effort and take the results as mere indication for the notion that strategic voting in German constituency elections occurs, albeit at a lower magnitude than usually found in plurality elections.

\section{Discussion}

This study aimed at providing evidence for strategic voting in constituencies of German Bundestag elections. Employing a decision theoretic approach, we formulated an individual-level model that allowed us to consider the full range of situations in which voters might potentially cast a strategic constituency ballot. We found evidence for sophisticated balloting in both elections under study, whereby voters adjust their behavior to the electoral situation in their local environment instead of merely going for the most preferred alternative. Specifically, the more likely a voter is to influence the race between her second and third preference and the stronger her preference between the two, the more likely she was found to vote for second preference, i.e. to vote strategically. On the other hand, the more likely she is to have an impact on the race between her first and second or first and third preference and the more she favors her first preference over the other two, the more likely she was found to vote for her first preference, i.e. to vote sincerely.

Coming back to the question posed in the beginning about the boundaries of voter sophistication, our model predictions suggest that strategic voting is not a large scale phenomenon at German federal elections. In fact, it appears to be of substantially smaller scale than what is commonly observed for pure FPTP systems, with the caveat that definitions and measurement as well as the actual amount strategic voting itself in a given election may vary between studies.

The theoretical framework and research strategy taken here is inspired by earlier attempts to uncover strategic voting in Canada (Black, 1978), Great Britain (Cain, 1978) or the US (Ordeshook and Zeng, 1997). The main advantages of assessing strategic voting in this way are flexibility and theoretical clarity. We started off with a general decision-theoretic model and adjusted it subsequently to fit the electoral situation in German constituencies. Strategic voting in other countries could be studied in a similar way. An even more informed perspective could be obtained by employing the above approach as a template for inter-temporal and cross-national comparisons. Thus, we might ask whether voters in different electoral systems, e.g. mixed vs. pure FPTP respond differently to electoral incentives? Likewise, we could investigate whether levels of strategic voting vary not only within but also between elections; for instance, do elections with many close races, on average, exhibit more strategic voting than elections with less competition on the constituency level? In comparing overall levels of strategic voting as well as voter elasticities towards local constituency races within and across countries we may gain more insights into the general conditions that give rise to strategic voting.

\section{Acknowledgments}

We thank Thomas Gschwend and two anonymous referees for many helpful suggestions and criticism. Any remaining errors are our own. 


\section{Appendix A}

\section{A.1. Construction of $P$ variables}

Let $E$ denote an election outcome between three candidates 1,2 and 3 , that is $E=\left(e_{1}, e_{2}, e_{3}\right)$. For simplicity, we consider outcomes where $e_{1}>e_{2}>e_{3}$. Given an election outcome $E$, a measure for the decisiveness of a vote in the race between candidates 1 and 2 can be constructed from the distance between $E$ and an outcome in which the two candidates would be tied for victory, while holding the share of the third candidate constant. Intuitively, this can be thought of as the minimum change in the election outcome required to make a single voter decisive (Black, 1978, 634). To express this formally, let $T$ denote any election outcome in which the two leading candidates would be tied for victory, i.e. $T=\left(t_{1}, t_{2}, t_{3}\right)$ with $t_{1}=t_{2}>t_{3}$. The Euclidian distance between outcomes $E$ and $T$ is defined as $\|E T\|=\left[\left(e_{1}-t_{1}\right)^{2}+\left(e_{2}-t_{2}\right)^{2}+\left(e_{3}-t_{3}\right)^{2}\right]^{1 / 2}$. Since, at $T$, candidates 1 and 2 obtain equal vote shares, $t_{1}=t_{2}=\left(e_{1}+e_{2}\right) / 2$. Furthermore, since the vote share of candidate 3 is held constant, $e_{3}=t_{3}$. Inserting these constraints into the Euclidian distance formula and rearranging yields the following simple expression:

$\|E T\|=\frac{1}{\sqrt{2}}\left(e_{1}-e_{2}\right)$

Note that, according to Black $(1978,636)$, the above constraints should lead to the expression

$\|E T\|=\left[\left(\frac{e_{1}}{2}\right)^{2}+\left(\frac{e_{2}}{2}\right)^{2}-e_{1} e_{2}\right]^{1 / 2}$

However, the correct result is

$\|E T\|=\left[\frac{e_{1}^{2}+e_{2}^{2}}{2}-e_{1} e_{2}\right]^{1 / 2}$

which can be further simplified to yield the above result. The distance measure in Eq. (4) reaches a maximum of $1 / \sqrt{2}$, i.e. if one candidate wins $100 \%$ of the vote. As can be seen from Eq. (4), the Euclidian distance of a given election result to a result in which 1 and 2 are tied for victory depends only on the district margin, i.e. the absolute difference between the vote shares of 1 and 2. Margin and Euclidian distance differ only by a scaling constant $1 / \sqrt{2}$. We normalize by dividing through the maximum, and subtract from one to obtain the measure $P_{12}$ :

$P_{12}=1-\sqrt{2}\|E T\|$
This measure takes on values from zero, if one candidate wins all votes, to one, if candidates 1 and 2 are tied for victory. As can be seen from Eqs. (4) and (5), our measure $P_{12}$ is equal to the complement of the district margin.

The above measures were defined with respect to $P_{12}$, the probability of being decisive between the two leading candidates. But they can also be used to compute the distance to a tie for the lead between candidates 1 and 3 , simply by replacing $e_{2}$ with $e_{3}$. However, calculating $\|E T\|$ is meaningful only if $e_{2} \leq 1 / 3$, i.e. the second finisher does not win more than one-third of the vote. Otherwise, if $e_{2} \leq 1 / 3,\|E T\|$ would be the distance to an outcome in which a voter would only be decisive in determining the second place between candidates 1 and 3 but not the winner, as the winner would be candidate 2 (see Black, 1978, 637). Thus, whenever the second place finisher obtains more than one-third of the vote, we calculate $P_{13}$ according to Eqs. (6) and (7), below.

For the calculation of $P_{23}$ we employ a different distance measure. As we are not interested in the distance of $E$ to the line of ties between candidates 2 and 3, because 2 and 3 both lose the election to 1 , the probability of being decisive between 2 and 3 is irrelevant to the election outcome unless candidate 1's share is altered. Following Black, we take the distance to a three-way tie $M=(1 / 3,1 / 3,1 / 3)$ as an indicator for the minimum change in 1, 2 and 3's shares required to make a voter decisive in determining victory between 2 and 3. Euclidian distance between $E$ and $M$ is given by:

$$
\|E M\|=\left[\left(e_{1}-\frac{1}{3}\right)^{2}+\left(e_{2}-\frac{1}{3}\right)^{2}+\left(e_{3}-\frac{1}{3}\right)^{2}\right]^{1 / 2}
$$

This distance measure reaches a maximum of $\sqrt{2 / 3}$. As above we normalize to obtain the measure:

$P_{23}=1-\sqrt{\frac{3}{2}}\|E M\|$

Together, the measures defined in Eqs. (5)-(7) suffice to compute all relevant $P$-variables for the analysis in Section 4.

\section{A.2. Feeling thermometer question}

"Generally speaking, what do you think of the parties? What do you think of [CDU, SPD, FDP, Greens, PDS]?" -5 "I think nothing of that party" to 5 "I think a great deal of that party" (translation is our own). 
+ MODEL

\section{References}

Alvarez, M.R., Nagler, J., 2000. A new approach for modelling strategic voting in multiparty elections. British Journal of Political Science 30, 57-75.

Bawn, K., 1993. The logic of institutional preferences: German electoral law as a social choice outcome. American Journal of Political Science 37, 965-989.

Bawn, K., 1999. Voter responses to electoral complexity: ticket splitting, rational voters and representation in the Federal Republic of Germany. British Journal of Political Science 29, 487-505.

Black, J.H., 1978. The multicandidate calculus of voting: application to Canadian federal elections. American Journal of Political Science 22, 609-638.

Blais, A., Nadeau, R., 1996. Measuring strategic voting: a two-step procedure. Electoral Studies 15, 39-52.

Blais, A., Nadeau, R., Gidengil, E., Nevitte, N., 2001. Measuring strategic voting in multiparty plurality elections. Electoral Studies 20, 343-352.

Blais, A., Young, R., Turcotte, M., 2005. Direct or indirect? Assessing two approaches to the measurement of strategic voting. Electoral Studies 24, 163-176.

Cain, B.E., 1978. Strategic voting in Britain. American Journal of Political Science 22, 639-655.

Cox, G.W., 1994. Strategic voting under the single nontransferable vote. American Political Science Review 88, 608-621.

Cox, G.W., 1997. Making Votes Count: Strategic Coordination in the World's Electoral Systems. Cambridge University Press, Cambridge.

Fisher, S.D., 2004. Definition and measurement of tactical voting: the role of rational choice. British Journal of Political Science 34, 125-166.

Fisher, S.L., 1973. The wasted vote thesis. West German evidence. Comparative Politics 5, 293-299.

Grofman, B., Chiaramonte, A., D’ Alimonte, R., Feld, S.L., 2004. Comparing and contrasting the uses of two graphical tools for displaying patterns of multiparty competition. Party Politics 10, 273-299.

Gschwend, T., 2007. Ticket-splitting and strategic voting under mixed electoral rules: evidence from Germany. European Journal of Political Research 46, 1-23.

Gschwend, T., Leuffen, D., 2005. Divided we stand - unified we govern? The issue of cohabitation in the French elections of 2002. British Journal of Political Science 35, 691-712.
Gschwend, T., Johnston, R., Pattie, C., 2003. Split-ticket patterns in mixed-member proportional election systems: estimates and analyses of their spatial variation at the German federal election, 1998. British Journal of Political Science 33, 109-127.

Hoffman, D.T., 1982. A model for strategic voting. SIAM Journal on Applied Mathematics 42 (4), 751-761.

Jesse, E., 1988. Split-voting in the federal republic of Germany: an analysis of the federal elections from 1953 to 1987. Electoral Studies 7, 109-124.

Katz, J.N., King, G., 1999. A statistical model for multiparty electoral data. American Political Science Review 93, 15-32.

McKelvey, R.D., Ordeshook, P.C., 1972. A general theory of the calculus of voting. In: Herndon, J., Bernd, J. (Eds.), Mathematical Applications in Political Science. University Press of Virginia, pp. 32-78.

Miller, W.L., 1977. Electoral Dynamics in Britain since 1918. Macmillan Press.

Myatt, D.P., 2007. On the theory of strategic voting. Review of Economic Studies 74 (1), 255-281.

Myerson, R.B., Weber, R.J., 1993. A theory of voting equilibria. American Political Science Review 87, 102-114.

Ordeshook, P.C., Zeng, L., 1997. Rational voters and strategic voting. Evidence from the 1968, 1980 and 1992 elections. Journal of Theoretical Politics 9, 167-187.

Palfrey, T.R., 1989. A mathematical proof of Duverger's law. In: Ordeshook, P.C. (Ed.), Models of Strategic Choice in Politics. University of Michigan Press, Ann Arbor, MI, pp. 69-91.

Pappi, F.U., Thurner, P.W., 2002. Electoral behaviour in a two-vote system: incentives for ticket splitting in German Bundestag elections. European Journal of Political Research 41, 207-232.

Roberts, G.K., 1988. The "second-vote" campaign strategy of the West German Free Democratic Party. European Journal of Political Research 16, 317-337.

Schoen, H., 1999. Split-ticket voting in German federal elections, 1953-90: an example of sophisticated balloting? Electoral Studies $18,473-496$

Upton, G.J.G., 1994. Picturing the 1992 British general election. Journal of the Royal Statistical Society 157, 231-252.

Wüst, A.M., Schmitt, H., Gschwend, T., Zittel, T., 2006. Candidates in the 2005 Bundestag election: mode of candidacy, campaigning and issues. German Politics 15, 420-438. 